
Military Technical College Kobry El-Kobbah, Cairo, Egypt.

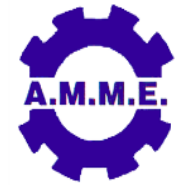
$18^{\text {th }}$ International Conference on Applied Mechanics and Mechanical Engineering.

\title{
EXPERIMENTAL STUDY ON GAS-SOLID MIXTURE FLOWS IN A VENTURI
}

\author{
T. A.Ghonim ${ }^{1, *}$, M. Sheha ${ }^{2}$, I. M. Sakr ${ }^{1}$ and W. A. El-Askary ${ }^{2}$
}

\begin{abstract}
The present paper concerns with studying experimentally the mixture of gas-solid (air-coal) flows in a Venturi meter in an attempt to prepare a metering tool for suspended gas-solid mixture flows. The different parameters that affect the gas-solid mixture flows metering process were determined and analyzed. In order to conduct the study, an experimental set-up was designed and manufactured in the laboratory of the thermal power engineering in Menoufia University. Furthermore, seven nonstandard (long-throated) geometrical Venturi models with different diameters ratios and throat lengths were selected guided by previous literature and manufactured to be used in the present experimental work. Additionally, the experimental study was performed on the selected models to determine the effect of different Venturi meter geometric models on pressure drop sensitivity, pressure recovery, and to seek a viable method for determining loading ratio for suspended gas-solid flows in the Venturi. The results showed that the coal loading ratio affected greatly and positively both the pressure drop and recovery ratios of air-coal mixture flows in the Venturi. However, inlet and exit geometries of the Venturi had smaller effect on the pressure drop and recovery ratios than the coal loading ratio and particles diameter range. Additionally, decreasing the diameters ratio and increasing the throat length improved the Venturi pressure drop sensitivity to solids loading. Finally, the experimental results helped greatly to analyze the different parameters concerning the air-coal mixture flows in a Venturi meter and provided an insight on the feasibility of using the Venturi as a metering tool for suspended gas-solid mixture flows in a future continuation of the present work.
\end{abstract}

\section{KEY WORDS}

Experimental study, Pressure drop and recovery, Venturi meter, Gas-solid mixture flows, and Loading ratio.

1 Lecturer, Dept. of Mech. Power Engineering, Faculty of Engineering, Menoufia University, Shebin El-Kom, Egypt.

2 Professor, Dept. of Mech. Power Engineering, Faculty of Engineering, Menoufia University, Shebin El-Kom, Egypt.

* Corresponding author E-mail: tarek_ghonim@sh-eng.menofia.edu.eg. 


\section{NOMENCLATURE}

$d_{\text {th }} \quad$ Throat diameter of the Venturi, $\mathrm{mm}$.

$D_{\text {in }} \quad$ Venturi inlet and exit diameters, $\mathrm{mm}$.

$D_{p} \quad$ Coal particle diameter, $\mu \mathrm{m}$.

$\Delta \mathrm{h} \quad$ The differential height of the manometer column.

$\mathrm{L}_{1} \quad$ Venturi convergent length, $\mathrm{mm}$.

$\mathrm{L}_{2} \quad$ Venturi throat length, $\mathrm{mm}$.

$\mathrm{L}_{3} \quad$ Venturi divergent length, $\mathrm{mm}$.

$\mathrm{L}_{\mathrm{T}} \quad$ Venturi total length, $\mathrm{mm}$.

M Mass of coal.

$\mathrm{M}^{\circ}{ }_{\mathrm{C}} \quad$ Coal mass flow rate $\left(\left(\mathrm{M}^{\circ}{ }_{\mathrm{C}}=\mathrm{M} / \mathrm{t}\right)\right.$.

$\mathrm{M}_{\mathrm{m}}^{\mathrm{o}} \quad$ Primary (motive) mass flow rate of the ejector.

$\mathrm{M}_{\mathrm{S}}{ }_{\mathrm{S}} \quad$ Secondary (suction) mass flow rate of the ejector.

$\mathrm{M}^{0}{ }_{\text {air }} \quad$ Air total mass flow rate, $\left(\mathrm{M}^{0}\right.$ air $\left.=\mathrm{M}_{\mathrm{s}}^{0}+\mathrm{M}_{\mathrm{m}}^{0}\right)$.

$\Delta \mathrm{P} \quad$ Pressure drop $(\Delta \mathrm{P}=\gamma \Delta \mathrm{h})$.

$\Delta \mathrm{P}_{\mathrm{G} 1} \quad$ Air pressure drop between the Venturi inlet and its throat.

$\triangle \mathrm{P}_{\mathrm{G} 2} \quad$ Air pressure recovery between the Venturi exit and its throat.

$\Delta \mathrm{P}_{\mathrm{TP} 1} \quad$ Air-coal pressure drop between the Venturi inlet and its throat.

$\triangle \mathrm{P}_{\mathrm{TP} 2} \quad$ Air-coal pressure recovery between the Venturi exit and its throat.

$\Delta \mathrm{P}_{\mathrm{TP} 1} / \Delta \mathrm{P}_{\mathrm{G} 1} \quad$ Pressure drop ratio.

$\Delta \mathrm{P}_{\mathrm{TP} 2} / \Delta \mathrm{P}_{\mathrm{G} 1} \quad$ Pressure recovery ratio.

$\mathrm{t} \quad$ Time.

$X_{\text {th }} \quad$ Distance from the Venturi inlet to throat pressure taps.

$\mathrm{X}_{\max } \quad$ Distance from the Venturi inlet to outlet pressure taps.

$\mathrm{Y} \quad$ Air mass flow rates ratio $\left(\mathrm{M}_{\mathrm{s}}^{\mathrm{O}} / \mathrm{M}_{\mathrm{m}}^{\mathrm{O}}\right)$.

$\mathrm{Z} \quad$ Solid (coal) loading ratio $\left(\mathrm{M}_{\mathrm{c}}{ }^{\mathrm{d}} / \mathrm{M}_{\mathrm{m}}^{\mathrm{O}}\right)$.

\section{GREEK SYMBOLS}

$\Theta_{1} \quad$ Venturi inlet angle.

$\Theta_{2} \quad$ Venturi exit angle.

$\beta \quad$ Diameters ratio $\left(d_{\mathrm{th}} / \mathrm{D}_{\mathrm{in}}\right)$.

$\rho_{\mathrm{c}} \quad$ Coal density.

$\gamma \quad$ Specific weight of water.

\section{INTRODUCTION}

Metering of solid flow rates in gas-solid flow mixtures has become increasingly vital in several of the chemical and energy-conversion industries. Moreover, measurement of the mass flow rate of pulverized coal in power plant pipelines is a key technology for the safety, economical operation, process performance and control of coal-fired 
boilers. Using a Venturi for metering a single phase fluids (gas or liquid) has been extensively investigated and standards have been adopted to measure the flow rate with a high degree of accuracy. However, the challenge is to extend the Venturi use to meter two phase (gas-solid) flow rate with acceptable accuracy degree. The advantages of a Venturi meter in metering two phase flow rate include its simplicity and low cost. Numerous researchers have studied experimentally and theoretically the use of differential pressure flow meters, especially a Venturi for flow rate measurements of solids in gas-particle suspensions. The pressure drop between the Venturi inlet and throat is strongly dependent on the solid particle size and the mass flow rate [1-3]. Furthermore, the pressure drop is related to solids loading because the quantity of particles present affects the ratio of the particle response time and the gas residence time in the Venturi [4]. Use of a Venturi for practical metering in power station must consider the overall pressure decrease across the Venturi, particle wear on the walls, and the sensitivity required for conducting sensible measurements [5].

The solid loading ratio in the coal fired power station varies between 0.3 and 1.0 approximately with a usual operating point between 0.3 and 0.5 . The variation of the Venturi throat gas velocity is more remarkable. Where, it may indicate a greater energy transfer with the presence of particles. The pressure drop of the gas-coal mixture increases with the increase of gas velocity, solid loading ratio and gas density [6\&7]. More recently, the Venturi diffuser section length and angle play an effective role in pressure recovering for the cases of no or light solid loading ratios. However, the effectiveness of the pressure recovery dropped rather rapidly as the solid loading ratio increased. On the other hand, the throat diameter ratio should be less than 0.7 to maintain high upstream pressures. For a larger diameter ratio, the gas-solid mixture is accelerated to higher velocity through the convergent section, and the pressure drop increases sharply [8-10]. Generally, the Venturi operation is governed by geometric and operational parameters. The geometric parameters include all the dimensions and angles of the convergent, constant-area and divergent tubes. While the operational ones include, for instance, the air mass flow rate in case of single-phase flow and solids loading ratio and average diameter range in case of two-phase flow.

The aim of this study is to perform the following: (1) design and fabrication of an experimental test-rig to prepare a two-phase (air-coal) mixture flows in order to pass it vertically upward through a Venturi tube in a closed loop cycle, (2) seven different geometric Venturi models will be manufactured guided by the previous literature in order to investigate their effects on both single and two-phase pressure drop, pressure distribution along the Venturi axis, and solids (coal) loading ratio, (3) investigating the effect of air mass flow rate on the single-phase (air) pressure drop and the solids loading ratio on the two-phase (air-coal) pressure drop, (4) investigating the effect of particle (coal) average diameter range on solids loading ratio and pressure distribution, and (5) gaining an insight on the feasibility of using the Venturi as a metering tool for suspended gas-solid mixture flows in a future continuation of the present work.

\section{EXPERIMENTAL SET-UP AND MEASUREMENT PROCEDURES}

Figure 1 illustrates schematically and photographically the experimental test rig, which was designed and manufactured to carry out the measurements of present 


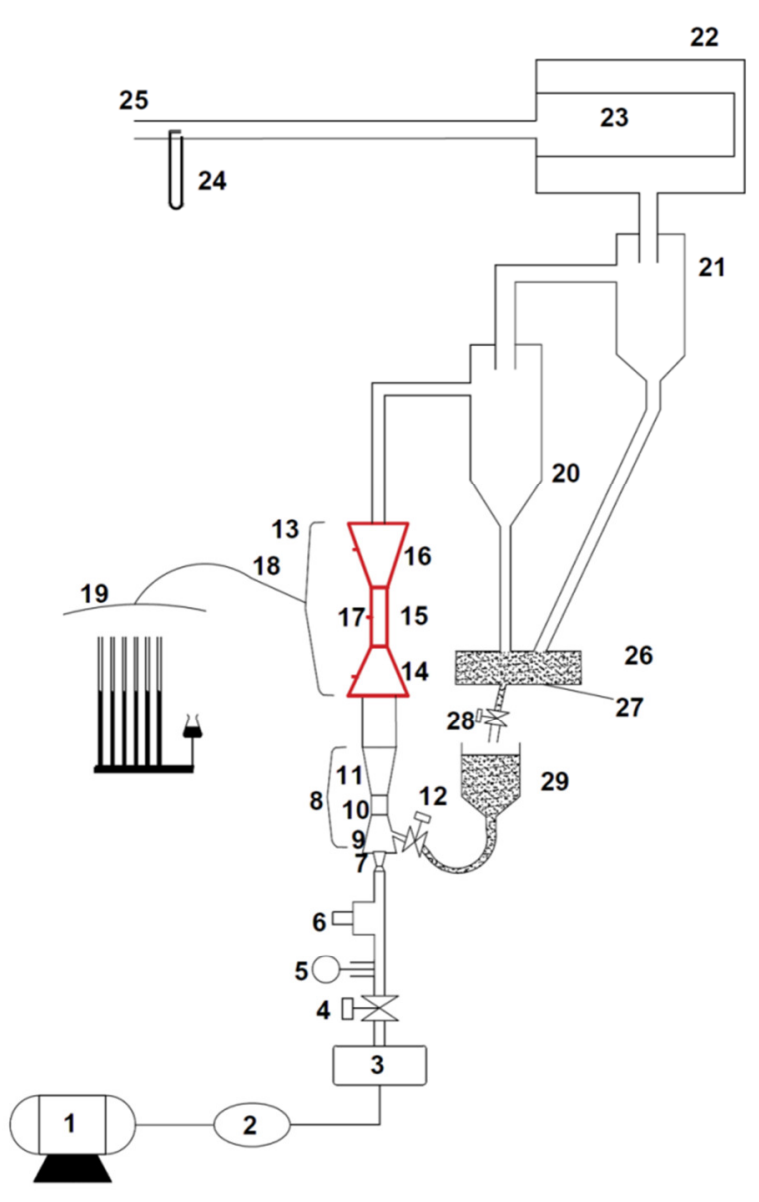

(a) Schematic diagram of the test rig.

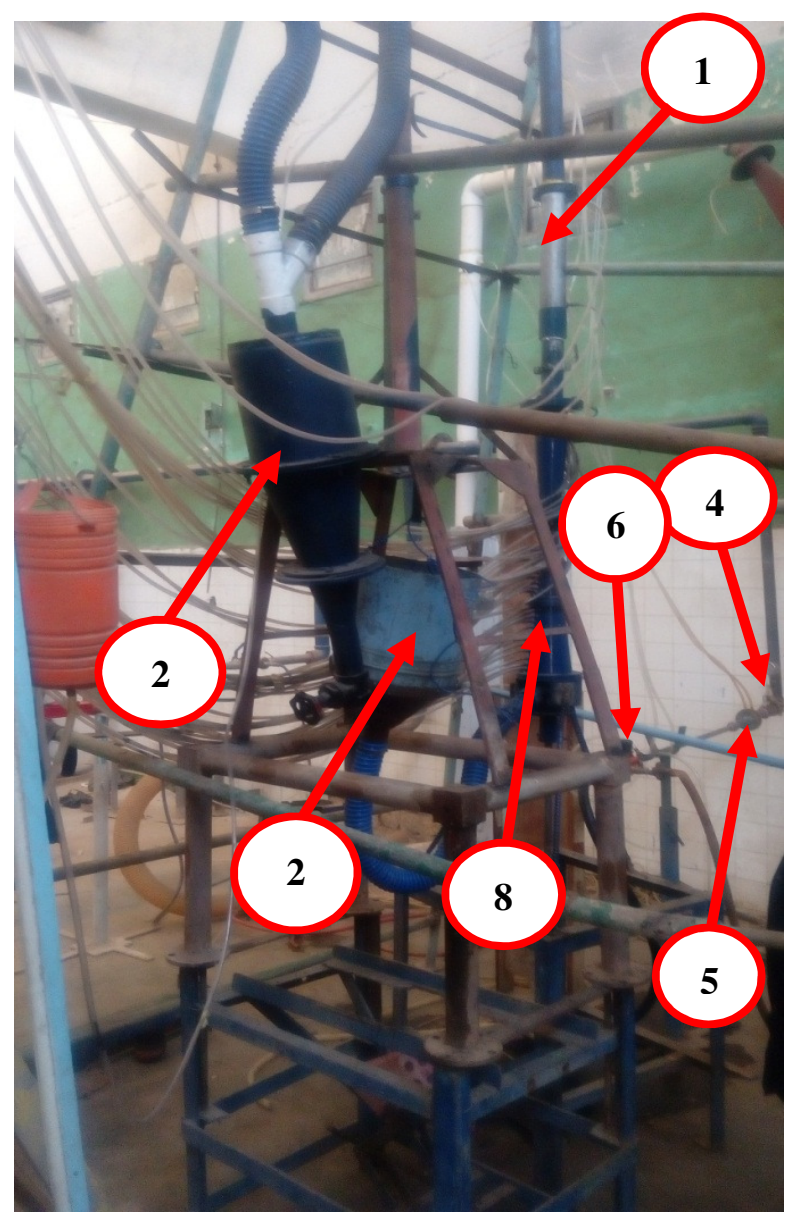

(b) Photograph of the test rig.

\begin{tabular}{|l|l|l|}
\hline 1- Screw compressor. & 2- Air filter. & 3- Air tank. \\
\hline 4- Pressure control valve. & 5- Orifice flow meter. & 6- Pressure regulator. \\
\hline 7- Primary flow convergent-divergent (supersonic) nozzle. & 8- Ejector. \\
\hline 9- Constant pressure mixing area. & 10- Constant area mixing section. \\
\hline 11- Diffuser section. & 12- Flow control valve. & 13- Venturi \\
\hline 14- Convergent section. & 15- Throat section. & 16- Divergent section. \\
\hline 17- Pressure taps. & 18- Bundle of pressure hoses. & 19- Multi-tube manometer. \\
\hline 20- First stage cyclone. & 21- Second stage cyclone. & 22- Exit air tank. \\
\hline 23- Air-coal trap. & 24- Pitot static tube. & 25- Air exit tube. \\
\hline 26- Secondary coal reservoir. & 27- Collected coal. & 28- Flow control valve. \\
\hline 29- Main coal reservoir. & & \\
\hline
\end{tabular}

Fig. 1. Layout of the experimental test rig.

work. The motive air flows in an open cycle. A screw compressor (1) is used to supply the required motive air after passing through an air filter (2). An air tank (3) supplies air steadily at a maximum gage pressure of 8 bars. The air flow is controlled, metered and regulated by a pressure control valve (4), an orifice flow meter (5) and a pressure regulator (6) respectively. The motive air is delivered to a primary flow convergent-divergent (supersonic) nozzle (7), which is placed along the axis of an ejector (8). The ejector is composed of convergent (9), constant (10), and divergent (11) area sections. Due to the negative pressure at the motive flow nozzle exit, coal or air is entrained to the ejector suction port. The flow rate of coal or air is controlled by a flow control valve (12) which is connected to the main coal reservoir (29) or left 
open to atmosphere. After being well mixed, the air-coal mixture flow is discharged to the Venturi (13). Moreover, three pressure taps (17) are made in the convergent, throat and divergent sections (14, 15 and 16 respectively) of the Venturi. These pressure taps are connected via pressure hoses (18) to multi-tube manometer (19) to measure the static pressure. The air-coal flow mixture then exits from the Venturi to a two-stage cyclone (20 and 21) for separating the coal which is drained to the secondary coal reservoir (26). The coal (27) is then passed to the main coal reservoir (29) through a flow control valve (28) to make a closed loop. On the other hand, air goes to an exit air tank (22) to pass through an air-coal trap (23) which collects tinny coal dust. Finally, air is discharged to atmosphere via an exit tube (25) after measuring the air flow rate by a Pitot static tube (24). Furthermore, the details of the Venturi geometry used in the experiments and the locations of the pressure taps are illustrated Fig. 2. The dimensions of seven Venturi geometries are summarized in Table 1. The coal flow rate is metered using a digital scale and a stopwatch where the mass of the coal reservoir (29) is measured before and after each experiment. The detailed dimensions of the ejector and its convergent-divergent nozzle used in the experimental work are given in previous work of the corresponding author [11].

The analysis of the uncertainty of the measurements is based on Kline and McClintock method [12]. The accuracies of the different performed measurements are summarized in Table 2.

\section{RESULTS AND DISCUSSION}

The present results concern with showing, discussing and analyzing the pressure distribution along the Venturi axis for two different flows, namely single-phase air flow and two-phase (air-coal) flows. The wall static pressure is measured at three points along the Venturi axis, as can be illustrated in Fig. 2. The air static pressure distributions along the Venturi axis at different air mass flow rates ratios for seven Venturi geometric models are illustrated in Fig. 3. It is apparently clear, for all the Venturi models, that there is a remarkable pressure drop in the Venturi throat due to the gradual decrease in the flow area. This could be explained by the fact that, if the flow area is decreased, the velocity will consequently increase for subsonic flow. Hence, the pressure at the Venturi throat will be decreased. Furthermore, the pressure at the Venturi outlet is recovered due to the gradual increase in the flow area (subsonic diffuser). However, the pressure drop from the Venturi inlet to its outlet is smaller than that from inlet to throat because the pressure at the Venturi outlet is recovered due to gradual increase in the flow area (subsonic diffuser). While, the pressure at the Venturi exit is still smaller than that at the Venturi inlet where there is always an unrecoverable pressure drop due to friction. Moreover, it can be seen clearly that increasing the total air mass flow rate, $\mathrm{M}^{\circ}$ air passing through the Venturi resulted in an increase in the static pressure at all points along the Venturi axis which is consistent with previous findings of El-Askary et al.[13].

In addition, Figs. 4 and 5 illustrate that the Venturi air pressure drop, $\Delta \mathrm{P}_{\mathrm{G} 1}$ and air pressure recovery, $\Delta \mathrm{P}_{\mathrm{G} 2}$ are generally increased, for the seven geometric models, by increasing the air mass flow rates ratio and consequently the air total mass flow rate, $\mathrm{M}^{\circ}$ air. This is apparently due to increasing the flow velocity and decreasing its pressure leading to larger pressure drop as can be clearly depicted in the figures and confirmed by the well-established result that the pressure drop is proportional to the 


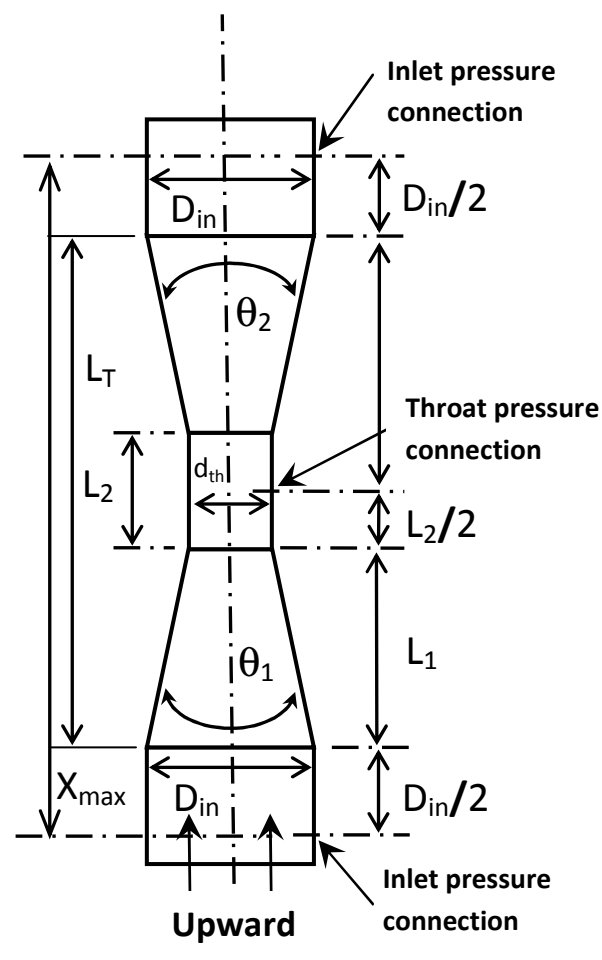

Flow

Fig. 2. details of the experimental Venturi geometry.

Table 1. Dimensions of the experimental Venturi models.

\begin{tabular}{|c|c|c|c|c|c|c|c|c|c|c|c|}
\hline Model & $\beta=d_{t h} / \mathbf{D}_{\text {in }}$ & $\boldsymbol{\Theta}_{1}$ & $\boldsymbol{\Theta}_{2}$ & $\mathbf{D}_{\text {in }}(\mathbf{m m})$ & $\begin{array}{c}\mathbf{d}_{\mathrm{th}} \\
(\mathbf{m m})\end{array}$ & $\begin{array}{c}\mathbf{L}_{1} \\
(\mathbf{m m})\end{array}$ & $\begin{array}{c}\mathbf{L}_{2} \\
(\mathbf{m m})\end{array}$ & $\begin{array}{c}\mathbf{L}_{3} \\
(\mathbf{m m})\end{array}$ & $\begin{array}{c}\mathbf{L}_{T} \\
(\mathbf{m m})\end{array}$ & $\begin{array}{c}\mathbf{X}_{\text {th }} \\
(\mathbf{m m})\end{array}$ & $\begin{array}{c}\mathbf{X}_{\max } \\
(\mathbf{m m})\end{array}$ \\
\hline 1 & 0.50 & $21^{\circ}$ & $8^{\circ}$ & 50.8 & 25.4 & 68.5 & 12.7 & 181.6 & 62.8 & 101 & 315.2 \\
\hline 2 & 0.60 & $12^{\circ}$ & $10^{\circ}$ & 50.8 & 30.5 & 96.7 & 63.5 & 116.1 & 276.3 & 154.6 & 328.7 \\
\hline 3 & 0.65 & $15^{\circ}$ & $4^{\circ}$ & 50.8 & 33 & 67.5 & 38.1 & 254.6 & 360.2 & 112.7 & 412.5 \\
\hline 4 & 0.71 & $18^{\circ}$ & $6^{\circ}$ & 50.8 & 36.1 & 46.5 & 25.4 & 140.5 & 212.4 & 85.3 & 265.3 \\
\hline 5 & 0.60 & $12^{\circ}$ & $10^{\circ}$ & 50.8 & 30.5 & 96.7 & 128.9 & 116.1 & 341.7 & 186.6 & 394 \\
\hline 6 & 0.65 & $15^{\circ}$ & 40 & 50.8 & 33 & 67.5 & 103.5 & 254.6 & 425.6 & 144.7 & 477.9 \\
\hline 7 & 0.71 & $18^{\circ}$ & $6^{\circ}$ & 50.8 & 36.1 & 46.5 & 90.8 & 140.5 & 277.8 & 117.3 & 330.7 \\
\hline
\end{tabular}

Table 2. Accuracies of the measured parameters.

\begin{tabular}{|c|c|c|c|c|c|c|c|}
\hline Variable & $\boldsymbol{\rho}_{\mathbf{c}}$ & $\Delta \mathbf{h}$ & $\Delta \mathbf{P}$ & $\mathbf{M}^{0}{ }_{\text {air }}$ & $\mathbf{M}^{\mathbf{0}}{ }_{\mathrm{c}}$ & $\mathbf{Z}$ & $\boldsymbol{\beta}$ \\
\hline Accuracy & $\begin{array}{c} \pm 12 \\
\mathrm{~kg} / \mathrm{m}^{3}\end{array}$ & $\begin{array}{c} \pm 0.05 \\
\mathrm{~mm}\end{array}$ & $\begin{array}{c} \pm 0.49 \\
\mathrm{~Pa}\end{array}$ & $\begin{array}{c} \pm 7.55 \\
\times 10^{-4} \\
\mathrm{Kg} / \mathrm{s}\end{array}$ & $\begin{array}{c} \pm 1.2 \\
\times 10^{-4} \\
\mathrm{Kg} / \mathrm{s}\end{array}$ & $\begin{array}{c} \pm 1.6 \\
\times 10^{-3}\end{array}$ & $\begin{array}{c} \pm 3.6 \\
\times 10^{-3}\end{array}$ \\
\hline
\end{tabular}



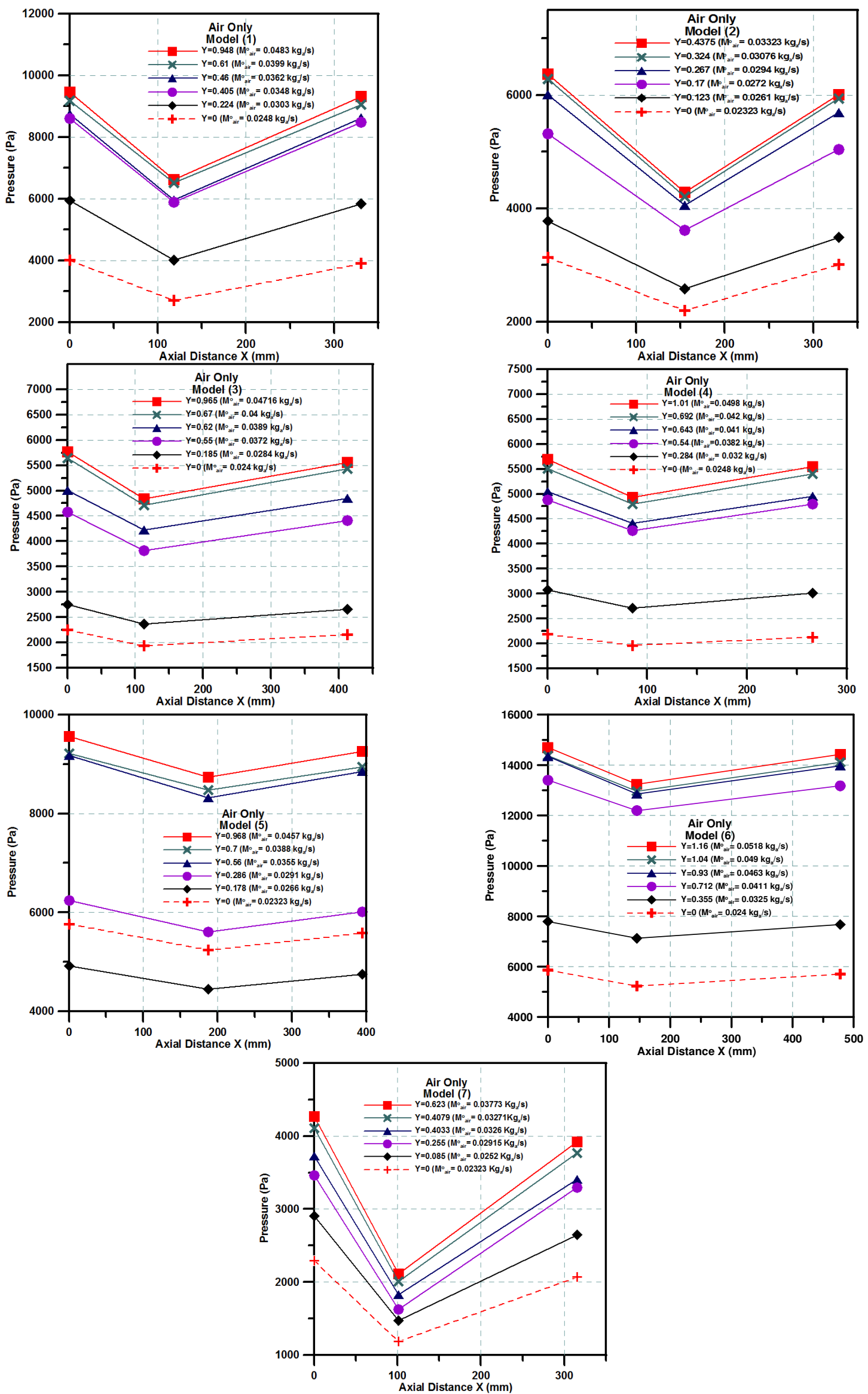

Fig. 3. Air wall static pressure distribution along the Venturi axis at different air mass flow rates ratio for seven experimental models. 


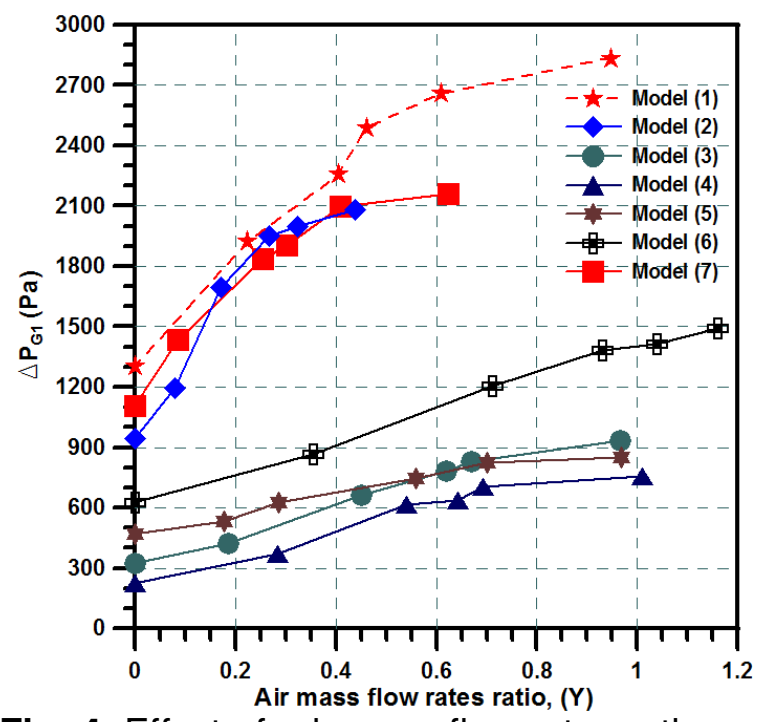

Fig. 4. Effect of air mass flow rates ratio on air pressure drop for seven different geometric models.

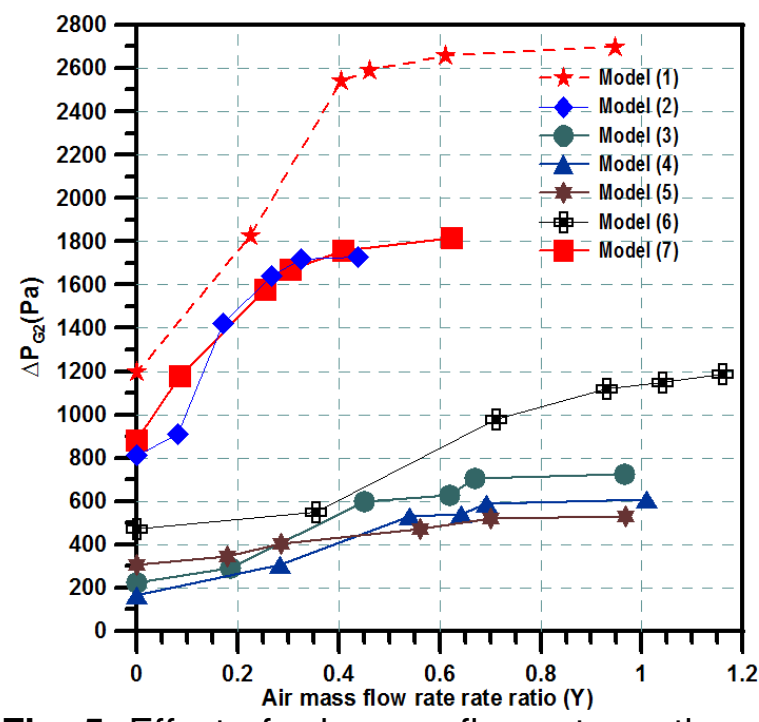

Fig. 5. Effect of air mass flow rates ratio on air pressure recovery for seven differentgeometric models.

square of the flow velocity. As can be shown in Fig. 4, Model (1) had the highest air pressure drop because it has the smallest throat diameter (smallest diameter ratio). Furthermore, Model (4) showed the lowest air pressure drop which is attributed to having the largest throat diameter ratio as well. Figure (5) indicates that Model (1) had the highest air pressure recovery while Model (4 and 5) showed the lowest air pressure recovery.

The air-coal wall static pressure distributions along the Venturi axis at different coal loading ratios and particle diameter ranges for seven Venturi geometric models are illustrated in Fig. 6. It is apparently remarkable that a similar scenario to that previously encountered in Fig. 3 is shown. Nevertheless, the wall static pressure distributions in the case of air-coal flows in a Venturi is correspondingly related to the particle content, namely the particle loading ratio, $Z$ and the particle diameter, $D_{p}$. Generally, increasing the coal loading ratio had a positive effect on the flow wall static pressure.

However, for some models increasing the particle loading ratio had a negative effect on the wall static pressure of the throat. A possible explanation for this behavior is the non-standard Venturi geometry represented in the long throat. When the Venturi throat is increased, the gas momentum lost in accelerating the particles is increased due to increasing both the gas residence and the particles response times in the throat. This loss of momentum of the gas manifests itself as a pressure loss. Furthermore, decreasing the particle diameter increased the wall static pressure in most of the geometric models as well. Nevertheless, for geometric model (3) decreasing the particle diameter decreased the wall static pressure. A possible explanation for this opposite behavior is that decreasing the particles size has two opposite effects on the momentum transfer from the gas phase to the solids phase. The first one is that as the particles size decreases they become larger in number and hence require more drag. The second, decreasing the particles size diminishes the slip velocity between the two phases as a result of gravity force effect, which in turn decreases the drag force. 

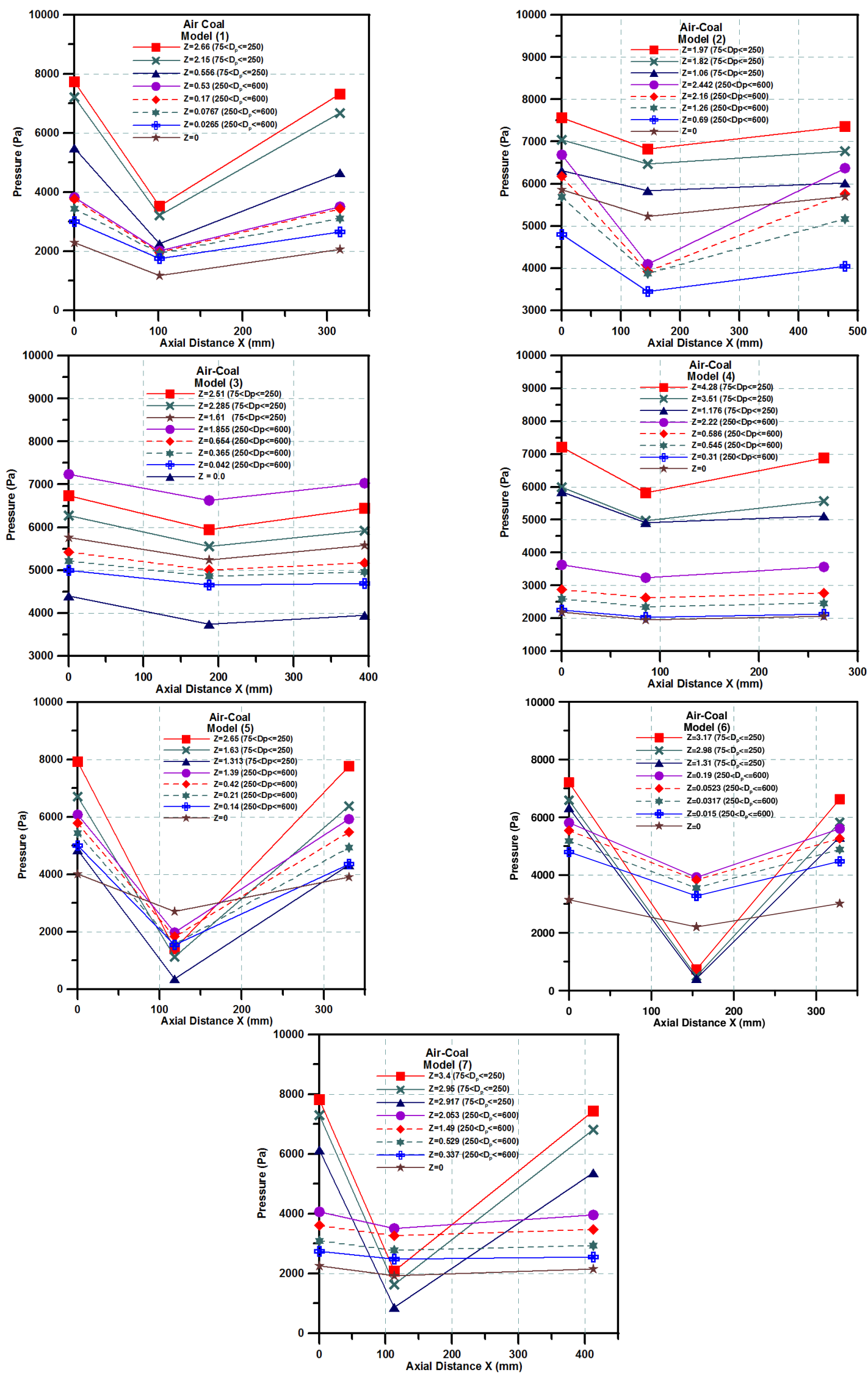

Fig. 6. Air-coal wall static pressure distribution along the Venturi axis at different coal loading ratios and particle diameter ranges for seven experimental models. 
Figures 7 and 8 depict the influence of coal loading ratio on pressure drop ratio for seven different geometric models for two coal diameter ranges $(75-250 \mu \mathrm{m})$ and $(250-$ $600 \mu \mathrm{m})$ respectively. It is worth noting that the Venturi differential pressure is correspondingly related to the particle content. In other words, the pressure drop ratio increased with increasing both solid loading ratio and solid particles diameter. Increasing the coal loading ratio enhances the momentum transfer from the gas phase to the solids phase. The gas phase becomes less kinetic due to accelerating the solid particles and consequently the pressure drop ratio increases in response. The particle concentration increases with increasing the solids loading ratio, which enhances the collision of the particles and the friction between particles and wall resulting in an increased pressure drop. For nearly constant coal loading ratio, the number of the smaller solid particles is higher than that of the larger ones and consequently the total surface area, which results in a larger drag force. Therefore, the momentum exchange increases as the particles size decreases. The smaller particles gain momentum at a higher rate as they respond faster to the gaseous flow. Similarly, Figures 9 and 10 depict the influence of coal loading ratio on pressure recovery ratio for seven different geometric models for two coal diameter ranges (75$250 \mu \mathrm{m})$ and $(250-600 \mu \mathrm{m})$ respectively as well. Moreover, the pressure drop and recovery ratios varied linearly with the particle loading ratio.

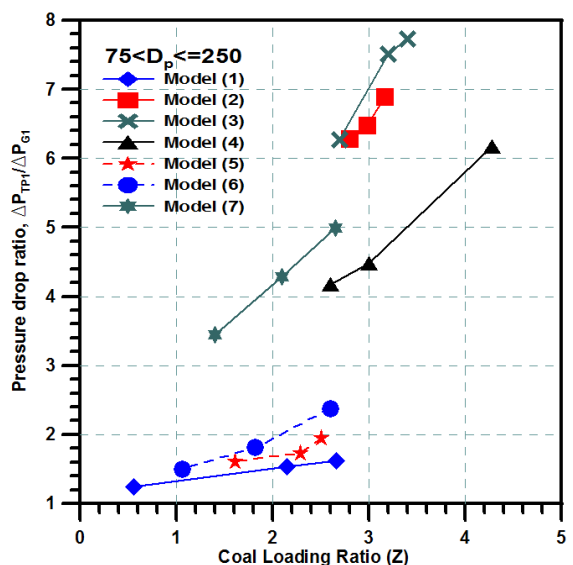

Fig. 7. Effect of coal loading ratio on pressure drop ratio for seven different geometric models for coal diameter range of $(75-$ $250 \mu \mathrm{m})$.

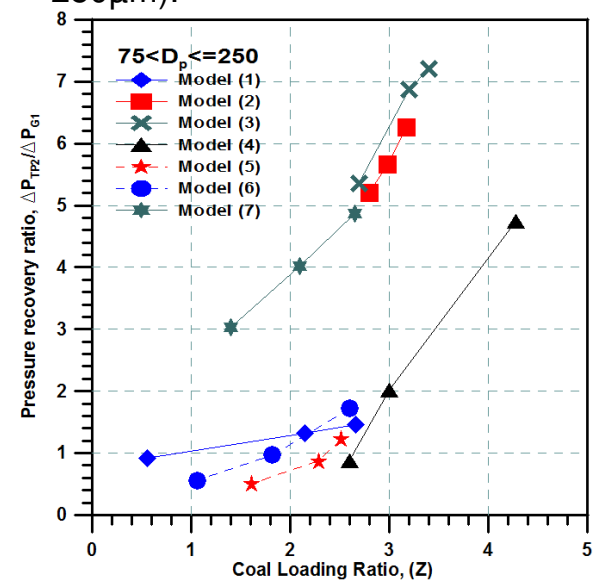

Fig. 9 Effect of coal loading ratio on pressure recovery ratio for seven different geometric models for coal diameter range of $(75-250 \mu \mathrm{m})$.

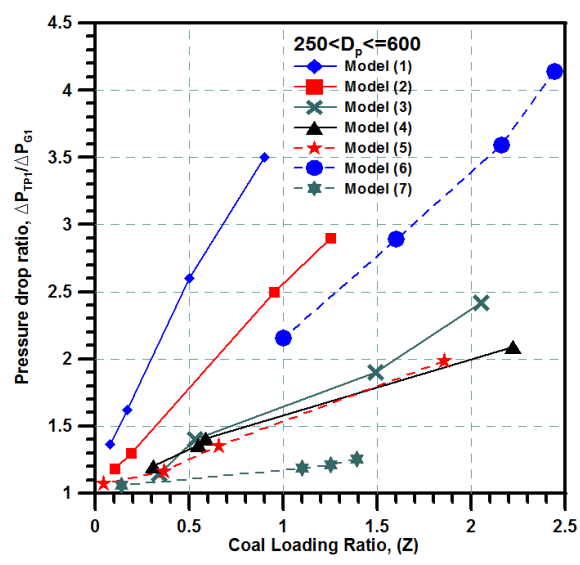

Fig. 8. Effect of coal loading ratio on pressure drop ratio for seven different geometric models for coal diameter range of (250$600 \mu \mathrm{m})$.

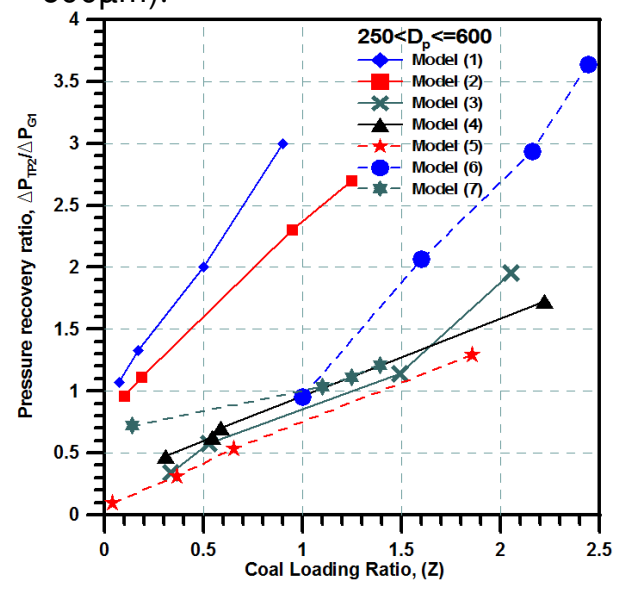

Fig. 10 Effect of coal loading ratio on pressure recovery ratio for seven different geometric models for coal diameter range of $(250-600 \mu \mathrm{m})$. 


\section{CONCLUSION}

The following items could be summarized:

1) The geometry of the Venturi is very crucial factor to improve differential pressure measurement precision and ensure stable measurements in metering gas-particle twophase flows.

2) The air pressure drop and recovery displayed nearly a curvilinear relation with the air mass flow rates ratio. However the pressure drop and recovery ratios displayed a linear relationship with the solid loading ratio.

3) The non-standard Venturi geometry (long throated) increased the gas residence time, which consequently increased the momentum exchange from gas to particles.

4) The air pressure drop of the Venturi was dominantly determined by the throat diameter. However the air-coal pressure drop ratio depended significantly on the throat length in the conducted experimental ranges.

5) The air-coal pressure drop and recovery ratios of the Venturi were greatly affected by the coal loading ratio and the particle mean diameter.

6) The Results provided a basis for further experimental study on preparing state-of-theart calibration correlations for metering air-coal mixture flows.

\section{REFERENCES}

[1] Richard H. Boll, "Particle collection and pressure drop in Venturi scrubbers", Chemical Engineering, 12, pp.40-50, (1973).

[2] Ezzat D. Doss, "Analysis and application of solid-gas flow inside a Venturi with particle interaction", Multiphase Flow, 11, pp.445-458, (1985).

[3] R. W. K. Allen, "Prediction of Venturi scrubber grade efficiency curves using the contacting power law", Powder Technology, 86, pp.137-144, (1996).

[4] B.J. Azzopardi, S.F.C.F. Teixeira and C.I. Pulford, "A quasi-one-dimensional model for gas-solids flow in Venturis", Powder Technology, 102, pp.281-288, (1999).

[5] D. Giddings, B.J. Azzopardi, A. Aroussi and S.J. Pickering, "Absolute measurement of pneumatically conveyed powder using a single long throat Venturi", Powder Technology, 172, pp.149-156, (2007).

[6] Haifeng Lu, Xiaolei Guo, Wanjie Huang, Kai Liu and Xin Gong, "Flow characteristics and pressure drop across the Laval nozzle in dense phase pneumatic conveying of the pulverized coal", Chemical Engineering and Processing, 50, pp.702-708, (2011).

[7] Kai Liu, Haifeng Lu, Xiaolei Guo, Xiaolin Sun, Shunlong Tao and Xin Gong, "Experimental study on flow characteristics and pressure drop of gas-coal mixture through Venturi", Powder Technology, 268, pp.401-411, (2014).

[8] Thiago Faggion de Pádua, Rodrigo Béttega and José Teixeira Freire, "Gas-solid flow behavior in a pneumatic conveying system for drying applications: coarse particles feeding with a Venturi device", Chemical Engineering, 5, pp.225-238, (2015).

[9] Cai Liang, John R. Grace, Liu Shen, Gaoyang Yuan, Xiaoping Chen and Changsui Zhao, "Experimental investigation of pressure letdown flow characteristics in dense-phase pneumatic conveying at high pressure", Powder Technology, 277, pp.171-180, (2015). 
[10] Haifeng Lu, Xiaolei Guo, Peng Li, Kai Liu and Xin Gong, "Design optimization of a venturi tube geometry in dense-phase pneumatic conveying of pulverized coal for entrained-flow gasification", Chemical Engineering, 120, pp.208-217, (2017).

[11] Hewedy N. I. I., Hamed M. H., Abou-Taleb F. Sh., and Tarek A. Ghonim, "Optimal Performance and Geometry of Supersonic Ejector," ASME J. Fluids Eng., 130, pp. 412-422, (2008).

[12] J.P. Holman, "Experimental methods for engineers", $7^{\text {th }}$ ed. McGraw-Hill, (2000).

[13] W.A. El-Askary, K.A. Ibrahim, S.M. El-Behery, Mofreh H. Hamed, and M.S. AlAgha, "Performance of vertical diffusers carrying Gas-solid flow: experimental and numerical studies", Powder Technology J., 273, pp. 19-32, (2015). 